\title{
In vivo and in vitro evidence that intrinsic upper- and lower- limb skeletal muscle function is unaffected by ageing and disuse in oldest-old humans
}

\author{
M. Venturelli, ${ }^{1,2}$ P. Saggin, ${ }^{3}$ E. Muti, ${ }^{4}$ F. Naro, ${ }^{5}$ L. Cancellara, ${ }^{6}$ L. Toniolo, ${ }^{6}$ C. Tarperi, ${ }^{2}$ \\ E. Calabria, ${ }^{2}$ R. S. Richardson, ${ }^{7,8,9}$ C. Reggiani ${ }^{6,10}$ and F. Schena ${ }^{2}$ \\ 1 Department of Biomedical Sciences for Health, University of Milan, Milan, Italy \\ 2 Department of Neurological, and Movement Sciences, University of Verona, Verona, Italy \\ 3 Division of Radiology and Imaging, City of Verona Diagnostic Center, Verona, Italy \\ 4 Mons. Mazzali Foundation, Mantova, Italy \\ 5 DAHFMO Unit of Histology and Medical Embryology, Sapienza University, Rome, Italy \\ 6 Department of Biomedical Sciences, University of Padova, Padova, Italy \\ 7 Division of Geriatrics, Department of Internal Medicine, University of Utah School of Medicine, Salt Lake City, UT, USA \\ 8 Geriatric Research, Education, and Clinical Center, George E. Wahlen Department of Veterans Affairs Medical Center, Salt Lake \\ City, UT, USA \\ 9 Department of Exercise and Sport Science, University of Utah, Salt Lake City, UT, USA \\ 10 CNR (Consiglio Nazionale delle Ricerche), Institute of Neuroscience, Padua, Italy
}

Received 6 January 2015, revision requested 6 February 2015

revision received 19 April 2015, accepted 7 May 2015

Correspondence: M. Venturelli, Department of Biomedical Sciences for Health, University of Milan, Via Colombo 71, 20133 Milano, Italy. E-mail: massimo. venturelli@unimi.it

\begin{abstract}
Aim: To parse out the impact of advanced ageing and disuse on skeletal muscle function, we utilized both in vivo and in vitro techniques to comprehensively assess upper- and lower-limb muscle contractile properties in 8 young (YG; $25 \pm 6$ years) and 8 oldest-old mobile (OM; $87 \pm 5$ years) and 8 immobile (OI; $88 \pm 4$ years) women.

Methods: In vivo, maximal voluntary contraction (MVC), electrically evoked resting twitch force (RT), and physiological cross-sectional area (PCSA) of the quadriceps and elbow flexors were assessed. Muscle biopsies of the vastus lateralis and biceps brachii facilitated the in vitro assessment of single fibre-specific tension (Po).

Results: In vivo, compared to the young, both the $\mathrm{OM}$ and $\mathrm{OI}$ exhibited a more pronounced loss of MVC in the lower limb [OM $(-60 \%)$ and OI $(-75 \%)]$ than the upper $\operatorname{limb}(\mathrm{OM}=-51 \%$; OI $=-47 \%)$. Taking into account the reduction in muscle PCSA $(\mathrm{OM}=-10 \%$; OI $=-18 \%)$, only evident in the lower limb, by calculating voluntary muscle-specific force, the lower limb of the OI $(-40 \%)$ was more compromised than the OM $(-13 \%)$. However, in vivo, RT in both upper and lower limbs (approx. $9.8 \mathrm{~N} \mathrm{~m} \mathrm{~cm}^{-2}$ ) and Po (approx. $123 \mathrm{mN} \mathrm{mm}^{-2}$ ), assessed in vitro, implies preserved intrinsic contractile function in all muscles of the oldest-old and were well correlated $(r=0.81)$.

Conclusion: These findings suggest that in the oldest-old, neither advanced ageing nor disuse, per se, impacts intrinsic skeletal muscle function, as assessed in vitro. However, in vivo, muscle function is attenuated by age and exacerbated by disuse, implicating factors other than skeletal muscle, such as neuromuscular control, in this diminution of function.

Keywords in vitro, in vivo, oldest-old, sarcopenia.
\end{abstract}


The age-related loss of skeletal muscle mass and the concomitant decline in muscle strength often contribute to the disability and ultimately the mortality associated with the elderly (Janssen et al. 2002, Metter et al. 2002, Narici \& Maffulli 2010, Sayer et al. 2013). The aetiology of this syndrome, sometimes termed sarcopenia, is multi-factorial and includes alterations in endocrine function, chronic disease, inflammation and nutritional disorders; however, ageing, per se, and muscle deconditioning caused by reduced physical activity appear to play a central role in this phenomenon (Doherty 2003, Fielding et al. 2011). Due to mobility limitations, primarily caused by a decline in both balance and ambulatory capacity, the oldest-old ( $>85$ years) are more prone to periods of lower-limb disuse (Buford et al. 2012, Pojednic et al. 2012, Dufour et al. 2013), which can result in a rapid and accelerated loss of maximal force and skeletal muscle mass, most commonly in the legs (Berg et al. 1997, Gallagher et al. 1997, Janssen et al. 2000, Raue et al. 2009, Venturelli et al. 2012). Although there are some studies evaluating older subjects (>70 years) and the impact of disuse in skeletal muscle (D'Antona et al. 2003, Suetta et al. 2007, 2009, Hvid et al. 2011), very little is known about the specific and combined physiological consequences of advanced ageing and disuse in the oldest-old.

Ageing, itself, has been proposed to lead to a multitude of adaptations in the neuromuscular system that are similar to those associated with disuse (Vandervoort 2002); therefore, it is difficult to discern the exclusive effect of ageing rather than simply the effect of disuse (Suetta et al. 2004, 2009, Suetta \& Kjaer 2010). However, it has been recognized that lowerlimb disuse in old subjects appears to exacerbate the age-related decline in the contractile function of the quadriceps muscles (Suetta et al. 2007, 2009), and the same age-disuse interaction pattern appeared to hold true when single skeletal muscle fibre mechanics were assessed in vitro (D'Antona et al. 2003, Hvid et al. 2011). Yet, no one has parsed out the effect of ageing and disuse by adopting the novel approach of examining skeletal muscle function in vivo and in vitro in both the upper- and lower-limb muscles, with the former exhibiting less of a reduction in use with age as they are not relied upon for locomotion.

Several factors differentiate in vitro single muscle fibre function from in vivo whole muscle function (Bottinelli et al. 1999, Erskine et al. 2009, Canepari et al. 2010b). For instance, MVC, assessed in vivo, is influenced by neuromuscular factors downstream from central command, such as motor neurone excitability and muscle voluntary activation (Hakkinen et al. 1998, Izquierdo et al. 1999, Aagaard et al. 2010). Additionally, in vivo, the volume of skeletal muscle mass recruited for a voluntary contraction and the muscle architecture (pennation angle) are the determining factors for in vivo force development (Campbell et al. 2013). However, the in vitro analysis of single muscle fibre function, such as the determination of maximal $\mathrm{Ca}^{2+}$-activated isometric force $(\mathrm{Fo})$, focuses on the intrinsic contractile properties of muscle fibres. Thus, in combination, in vivo and in vitro assessments of skeletal muscle function should better parse out the contribution of the multitude of factors that are recognized to play a role in the age- and disuse-induced reduction in skeletal muscle force.

Utilizing both in vivo and in vitro approaches, this study sought to investigate the unique and combined effects of advanced ageing and long-term disuse on skeletal muscle function. Specifically, by studying the upper- and lower-limb muscles of OM (old mobile) and OI (old immobile, wheelchair bound) subjects, in comparison with the YG (healthy young), we tested the following hypotheses: (1) the lower-limb muscle of the OM and OI subjects, assessed both in vivo and in vitro, would exhibit attenuated muscle function, (2) if this in vivo and in vitro decrement in muscle function could be explained, perhaps at least partially, by the complex muscle-specific process of sarcopenia which may be accelerated by inactivity, the diminished function would therefore be more pronounced in the OI subjects, and (3) the upper-limb muscle of the OM and OI subjects, both in vivo and in vitro, would exhibit similarly attenuated muscle function, which could be attributed solely to ageing.

\section{Material and methods}

\section{Subject characteristics}

Twenty-four women, 8 YG (range 23-26 years), 8 OM (range 85-92 years), and 8 OI (range 8690 years), volunteered and were approved to participate in this study based upon a physician's assessment of minimal cognitive, cardiovascular and musculoskeletal disease. This screening included a health history, a physical examination, an evaluation of lower-limb mobility (Tinetti 1986), an upper-limb activities of daily living performance test (Yozbatiran et al. 2008), a blood pressure assessment, a blood sample and a familiarization with the study exercise procedures. The local Ethics Committee approved the study, and all experimental procedures were performed in accordance with the Declaration of Helsinki. Written, informed consent was obtained from all participants before inclusion in the study. The young subjects were normally physically active college students. The OM subjects were all community dwelling, but able to 
walk independently (Tinetti 1986). The OI subjects were selected from residents of the Mons. Mazzali Foundation, geriatric institute of Mantua, Italy. The medical staff recruited oldest-old women who at the time of the study were mobility limited in lower limbs (2 years of being wheelchair bound) and unable to stand up from a chair and walk independently (Tinetti 1986). The diagnosis of altered gait capacity, poor balance and an elevated risk falling was the cause of this lower-limb mobility restriction.

\section{Upper- and lower-limb muscle volume}

Magnetic resonance images (MRI) was performed using a clinical 1.5 Tesla MRI system (GE Signa hdxt, Fairfield, CT, USA). T1-weighted images of the upper arm and thigh were acquired supine with the legs extended and the right arm adjacent to the trunk, elbow extended, supported on a foam pad. Images were obtained using a turbo spin echo sequence (slice thickness $=8.00 \mathrm{~mm}, \quad$ gap thickness $=8-10 \mathrm{~mm}$, turbo factor $=3$, TE $=8-12 \mathrm{~ms} ; \mathrm{TR}=550 \mathrm{~ms}$; concatenation $=2$, field of view $=25 \times 25$ and $20 \times 20 \mathrm{~cm}$; matrix size $=384 \times 384$ ) with $12-18$ axial slices from the top of the humerus to the elbow (arm) and 16-20 axial slices from the greater trochanter to the knee (thigh). The anatomic cross-sectional area of each scan was measured three times by a trained investigator, blinded to the subject's group, using the public domain image-processing software, IMAGE-J v1.46r (National Institute of Health, Bethesda, md, USA). On the basis of a signal-intensity threshold, muscle borders were selected to delineate and differentiate muscle, fat, and connective tissue, and the coefficient of variation between consecutive measurements was $<5 \%$. In the upper arm, the biceps brachii and brachialis muscles were identified in each slice and grouped together to constitute the elbow flexors (EF). Similarly, in the thigh area, the vastus lateralis (VL), vastus medialis, vastus intermedius and rectus femoris were traced in each image and in combination made up of the quadriceps (Q). EF and Q muscle volumes were then calculated by summing the areas of all the slices, taking into account the slice thickness and the interslice space (Deschenes et al. 2001). Muscle length was assessed as the distance between the most proximal and the most distal images in which the muscle was visible.

\section{Muscle architecture}

The physiological cross-sectional area (PCSA) (Petrella et al. 2008) was calculated in the arm by dividing $\mathrm{EF}$ muscle volume by the fascicle length $(\mathrm{Fl})$. Fl was calculated by multiplying muscle length (measured by MRI) by the fibre length-to-muscle length ratio, as previously reported in an autopsy-based study (Murray et al. 2000):

$\mathrm{PCSA}_{\mathrm{EF}}=\mathrm{EF}_{\mathrm{vol}} / \mathrm{Fl}$

In the thigh, sagittal ultrasound images of the VL muscle were recorded with a Siemens ACUSON P50 ultrasound system (Siemens AG, Munich, Germany) equipped with an $8-12 \mathrm{MHz}$ linear transducer. Images were obtained with a $90^{\circ}$ flexion of hip and knee, at $50 \%$ of femur length corresponding to the mid-belly of the VL muscle. The pennation angle $\left(\theta_{\mathrm{p}}\right)$ of the VL fascicles was measured as the angle between the VL muscle fascicles and the deep aponeurosis of the insertion. PCSA of the Q muscle was then calculated as the product of muscle volume times the cosine of $\theta_{\mathrm{p}}$ divided by the Fl (Powell et al. 1984):

$\mathrm{PCSA}_{\mathrm{Q}}=\mathrm{Q}_{\mathrm{vol}} \cdot \cos \theta_{\mathrm{p}} / \mathrm{Fl}$

\section{In vivo experimental set-up}

Maximal voluntary and electrically evoked muscle contractions of the EF and Q muscles were measured utilizing a custom-made set-up (Fig. 2, Panel a). Subjects were seated in an upright position with back support, and the right elbow was flexed to $90^{\circ}$, with the right hand supinated and the fingers extended. The hip and the knee were flexed at $90^{\circ}$, and both the right wrist and the right ankle were attached, via two straps and rigid steel bars, to the two force transducers (DBBSE-100 kg, A2829. Applied Measurements, Aldermaston Berkshire, UK). The output from the force transducers was amplified (INT2-L; London Electronics, Sandy Bedfordshire, UK) and recorded at a sampling rate of $5 \mathrm{KHz}$ with a PowerLab-16/35 data acquisition system (ADInstruments, Bella Vista, NSW, Australia).

\section{Voluntary- and RT-specific force}

$\mathrm{Q}$ and EF voluntary muscle-specific force was calculated by dividing fascicle force, estimated from measurements of the EF and $\mathrm{Q}$ isometric maximal voluntary contraction (MVC), by the PCSA of the corresponding muscles (Maganaris et al. 2001). Similarly, RT-specific force was calculated by dividing fascicle force, estimated in this case from the measurements of EF and Q electrically evoked RT, by the PCSA of the corresponding muscles (Maganaris et al. 2001).

Voluntary- and RT-specific force $=$ fascicle force $/$ PCSA 


\section{Electromyography}

M-waves were recorded from the biceps brachii and triceps brachii in response to brachial plexus stimulation, while during femoral nerve stimulation, M-waves were recorded in the VL and biceps femoralis muscles (detailed in next section). Pairs of full-surface solid adhesive hydrogel electrodes (H59P; Tyco Healthcare Group, Mansfield, MA, USA) were positioned lengthwise over the respective muscle bellies, with an interelectrode distance (centre to centre) of $20 \mathrm{~mm}$. The ground electrodes were fixed over the ipsilateral elbow and patella. Light skin abrasion followed by skin cleansing kept electrical impedance below $10 \mathrm{k} \Omega$. EMG signals were amplified with a pass-band of $10 \mathrm{~Hz}-1 \mathrm{kHz}$ and digitized online at a sampling frequency of $5 \mathrm{kHz}$.

\section{$E F$ and $Q$ nerve stimulation}

Each test procedure began with the determination of the maximal $\mathrm{M}$-wave and $\mathrm{RT}$ responses in the resting EF and Q muscles. Briefly, current intensity was progressively increased from $0 \mathrm{~mA}$ to the value beyond which there was no further increase in M-wave amplitude. The stimulus utilized for the study was set at the $125 \%$ of the intensity required to produce a maximal $\mathrm{M}$-wave response. For EF, electrical stimuli were delivered using circular (diameter $5.0 \mathrm{~cm}$ ), self-adhesive electrodes (Dermatrode; American Imex, Irvine, CA, USA) attached to the brachial plexus at Erb's point. The cathode was in the supraclavicular fossa, and the anode was over the acromion. The femoral nerve was stimulated with the cathode positioned in the femoral triangle, $3-5 \mathrm{~cm}$ below the inguinal ligament, and the anode placed over the iliac crest (Fig. 2, Panel a). The RT was evoked in the passive muscle using electrical stimulation consisting of single squarewave pulses of 0.1 -ms duration, delivered by a Digitimer DS7 constant-current stimulator (Digitimer, Welwyn Garden City, UK). The RT was measured $5 \mathrm{~s}$ after a 5-s MVC of the EF, and this procedure was repeated six times. Hence, it should be noted that RT was assessed in the potentiated state. With a 5-min interval, the same procedure was repeated for the $Q$ muscle. The interval between the MVCs was $30 \mathrm{~s}$. Peak torque was assessed for each RT (Sandiford et al. 2005). Voluntary activation of the EF and $Q$ muscles during the MVCs was assessed using a superimposed twitch technique (Merton 1954). Briefly, the force produced during a single twitch superimposed on the MVC was compared with the force produced by the electrically evoked RT produced, at rest, $5 \mathrm{~s}$ after the MVC.

\section{Muscle biopsies and in vitro single muscle fibre analysis}

On a separate day, a sample of skeletal muscle was obtained with a 14-gauge tru-cut needle (Paoli et al. 2010) from both the vastus lateralis and biceps brachii. The muscle samples were immediately immersed in high potassium, high EGTA solution, often described as skinning solution (details below), mixed in equal parts with glycerol. Once immersed in this solution, the sample could be stored at $-20^{\circ} \mathrm{C}$ for up to 2 weeks. On the day of the in vitro experiment, the samples were washed with skinning solution containing ATP, and the single fibres were manually dissected under a stereomicroscope and permeabilized with $1 \%$ Triton X-100. Fibre segments of the average length of $0.7 \mathrm{~mm}$ were mounted, by means of light aluminium clips, between the force transducer (model AME-801; SensorOne, Sausalito, CA, USA) and the motor (SI, Heidelberg, Germany) equipped with a displacement transducer. The fibre segment was immersed in a drop of relaxing solution and, after measuring length, diameters and sarcomere length at $400 \times$ magnification, was stretched by $20 \%$. Cross-sectional area (CSA) was calculated from the measurement of these three diameters (at $400 \times$ magnification) assuming the fibre to have a cylindrical shape. The fibre was then transferred into the preactivating solution and finally maximally activated by immersion in the activating solution ( $\mathrm{pCa} 4.6)$ at $12{ }^{\circ} \mathrm{C}$. Fo was measured in four subsequent maximal activations and the average value calculated. The fibre segment was then removed from the force assessment system and stored in Laemmli solution for electrophoretic determination of $\mathrm{MyHC}$ isoform composition.

Skinning, relaxing, pre-activating and activating solutions were prepared, as previously described (Toniolo et al. 2007). Their millimolar composition was as follows: 1) skinning solution contained $150 \mathrm{~K}$-propionate, $5 \mathrm{Mg}$ acetate, $5 \mathrm{ATP}, 5$ EGTA and $5 \mathrm{KH}_{2} \mathrm{PO} 4$; 2) relaxing solution contained 100 $\mathrm{KCl}, 20$ imidazole, $5 \mathrm{MgCl}_{2}, 5$ ATP and 5 EGTA. Pre-activating solution was similar to relaxing solution except that EGTA concentration was reduced to 0.5 and $25 \mathrm{~mm}$ creatine phosphate and $300 \mathrm{U} \mathrm{mL}^{-1}$ creatine kinase was added, whereas activating solution was similar to relaxing solution with the addition of $5 \mathrm{mM} \mathrm{CaCl}_{2}, 25 \mathrm{~mm}$ creatine phosphate and $300 \mathrm{U} \mathrm{mL}^{-1}$ creatine kinase. The $\mathrm{pH}$ of all solutions was adjusted to 7.0 at the temperature at which the solutions were used $\left(12^{\circ} \mathrm{C}\right)$. Protease inhibitors (10 $\mathrm{uM}$ E-64 and $40 \mathrm{uM}$ leupeptin) were present in all solutions. 
Each fibre was characterized by CSA, Fo and Po, determined by normalizing Fo by fibre CSA and then classified according to its MyHC isoform composition which was determined with gel electrophoresis, as described below. To ensure that the response of each subject was equally represented, the fibres from a given subject were pooled to calculate an individual weighted mean (Doria et al. 2011). Bundles of fibres remaining on the dissection plate at the end of the dissection were spread on a slide, images were taken at $400 \times$ magnification, and CSA was determined from diameter measurement as performed for the fibres studied in the contraction experiments.

Proteins for gel electrophoresis were prepared from the remains of the sample after single fibre dissection and from a sample, specifically collected for this purpose. The tissue samples were solubilized in Laemmli solution $(62.5 \mathrm{~mm}$ Tris, $\mathrm{pH}$ 6.8, 10\% glycerol, 2.3\% SDS, $5 \% \quad \beta$-mercaptoethanol, with $0.1 \%$ E-64 and $0.1 \%$ leupeptin as antiproteolytic factors). After heating for $5 \mathrm{~min}$ at $80{ }^{\circ} \mathrm{C}$, appropriate amounts of the protein suspension were loaded onto polyacrylamide gels (about $1 \mu \mathrm{g}$ of total protein/lane). For single fibre identification, the whole fibre segment was solubilized in $10 \mu \mathrm{L}$ of Laemmli solution, and $2-3 \mu \mathrm{L}$ was loaded onto gels. The separation of $\mathrm{MyHC}$ isoforms was achieved on $8 \%$ polyacrylamide slab gels with a protocol derived from Talmadge and Roy (Talmadge \& Roy 1993), with some minor modifications. Slabs - $18 \mathrm{~cm}$ wide, $16 \mathrm{~cm}$ high and $1 \mathrm{~mm}$ thick - were used. Electrophoresis was run at $4{ }^{\circ} \mathrm{C}$ for $24 \mathrm{~h}$, at $70 \mathrm{~V}$ for $1 \mathrm{~h}$ and $230 \mathrm{~V}$ for the remaining time. Three bands were separated in the region of $200 \mathrm{kDa}$, corresponding (in order of migration from the fastest to the slowest) to MyHC-1, MyHC-2A and MyHC-2X. Gels were silver stained (Life Science Bio-Rad Laboratories S.r.l., Milan, Italy) for single fibre identification or stained with Coomassie Blue for the determination of the relative proportions of the three $\mathrm{MyHC}$ isoforms. The relative proportions of $\mathrm{MyHC}$ isoforms were determined with the measurement of the brightness-area product B.A.P. (i.e. the product of the area of the band by the average brightness, subtracted from local background after black-white inversion) with the accuracy of $600 \mathrm{dpi}$.

\section{Statistical analyses}

Two-way ANOva was used to establish differences between groups and limbs. Following these analyses, where indicated, a Tukey post hoc test was used to determine the group differences. Pearson correlation test was used to examine the relationship between variables. Significance was set at an $\alpha$ level of 0.05 , and the results are presented as mean \pm SE.

\section{Results}

\section{Subject characteristics}

The physical characteristics of the YG, OM and OI are documented in Table 1. Body weight of the participants was significantly reduced in the OM and OI. Additionally, the YG women were taller than the two oldest-old groups. By experimental design, the YG and OM were normally active individuals with typical and similar upper- and lower-limb mobility. The upper-limb function and activity in the OI was not different from the YG and OM, whereas, in contrast, the ambulatory capacity of the OI, and therefore the lower limb, use was significantly attenuated. Compared to the YG, both the OM and OI exhibited higher systolic blood pressure, blood glucose, low-density lipoprotein and a lower blood haemoglobin concentration.

Table I Subject's characteristics

\begin{tabular}{|c|c|c|c|}
\hline & YG & $\mathrm{OM}$ & OI \\
\hline Age (years) & $25 \pm 2$ & $87 \pm 5 *$ & $88 \pm 4^{*}$ \\
\hline $\begin{array}{l}\mathrm{BMI} \\
\left(\mathrm{kg} \mathrm{m}^{-2}\right)\end{array}$ & $23 \pm 4$ & $21 \pm 3$ & $22 \pm 4$ \\
\hline $\begin{array}{l}\text { Body } \\
\text { weight }(\mathrm{kg})\end{array}$ & $69 \pm 4$ & $52 \pm 5^{*}$ & $54 \pm 3^{*}$ \\
\hline Stature $(\mathrm{m})$ & $1.75 \pm 0.05$ & $1.57 \pm 0.03 *$ & $1.58 \pm 0.04 *$ \\
\hline $\begin{array}{l}\text { SBP } \\
(\mathrm{mmHg})\end{array}$ & $118 \pm 4$ & $135 \pm 5^{*}$ & $133 \pm 6^{*}$ \\
\hline $\begin{array}{l}\text { DBP } \\
(\mathrm{mmHg})\end{array}$ & $82 \pm 4$ & $86 \pm 6$ & $87 \pm 8$ \\
\hline $\begin{array}{l}\text { Glucose } \\
\left(\mathrm{mg} \mathrm{dL}^{-1}\right)\end{array}$ & $86 \pm 3$ & $95 \pm 8^{*}$ & $96 \pm 7^{*}$ \\
\hline $\begin{array}{l}\mathrm{RBC} \\
\left(10^{6} \mu \mathrm{L}^{-1}\right)\end{array}$ & $4.2 \pm 0.1$ & $4.0 \pm 0.2$ & $3.9 \pm 0.3$ \\
\hline $\begin{array}{l}\mathrm{Hb} \\
\left(\mathrm{g} \mathrm{dL}^{-1}\right)\end{array}$ & $13.6 \pm 0.4$ & $11.6 \pm 0.5^{*}$ & $11.2 \pm 0.8^{*}$ \\
\hline $\begin{array}{l}\mathrm{HDL} \\
\left(\mathrm{mg} \mathrm{dL}^{-1}\right)\end{array}$ & $51 \pm 8$ & $52 \pm 9$ & $54 \pm 6$ \\
\hline $\begin{array}{l}\mathrm{LDL} \\
\left(\mathrm{mg} \mathrm{dL}^{-1}\right)\end{array}$ & $96 \pm 10$ & $107 \pm 11^{*}$ & $110 \pm 14^{*}$ \\
\hline \multicolumn{4}{|c|}{ Lower-limb mobility capacity } \\
\hline $\begin{array}{l}\text { Balance } \\
\text { test }(0-16)\end{array}$ & $16 \pm 0$ & $16 \pm 0$ & $1 \pm 1^{* \dagger}$ \\
\hline $\begin{array}{l}\text { Gait } \\
\text { test }(0-12)\end{array}$ & $12 \pm 0$ & $12 \pm 0$ & $0 \pm 0^{*} \dagger$ \\
\hline \multicolumn{4}{|c|}{ Upper-limb performance score of activities of daily living } \\
\hline $\begin{array}{l}\text { ARAT } \\
\text { test }(0-57)\end{array}$ & $57 \pm 0$ & $55 \pm 3$ & $55 \pm 2$ \\
\hline
\end{tabular}

Data are presented as means $\pm \mathrm{SE}$. BMI, body mass index; SBP, systolic blood pressure; DBP, diastolic blood pressure; $\mathrm{RBC}$, red blood cells; Hb, haemoglobin; HDL high-density lipoprotein; LDL, low-density lipoprotein.

"Significantly different from young subjects.

${ }^{\dagger}$ Significantly different from old-mobile subjects. 

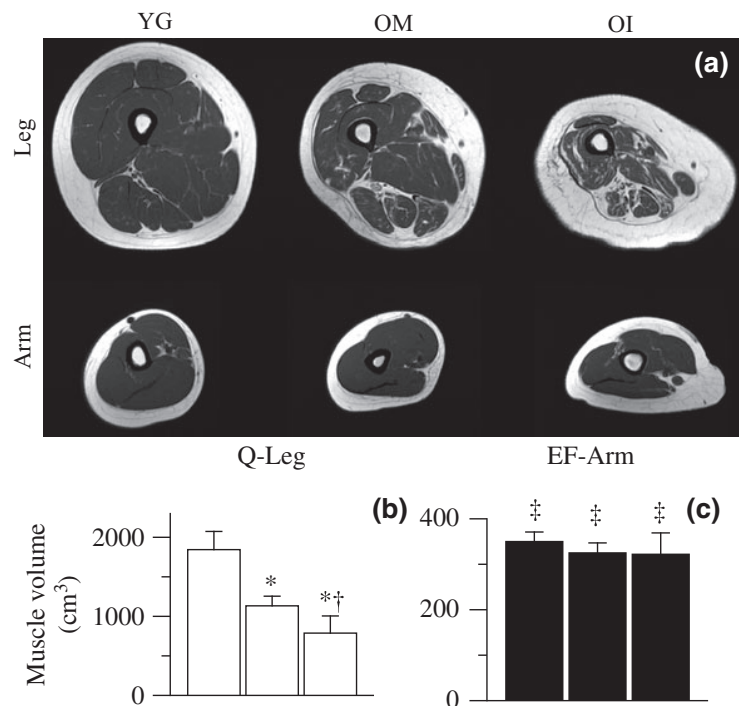

(b)
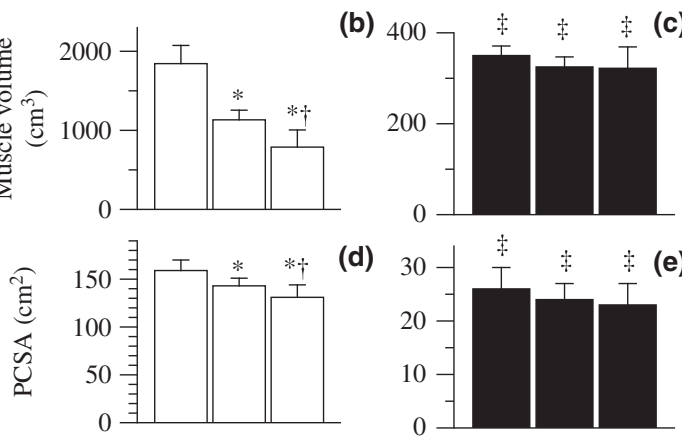

(d)
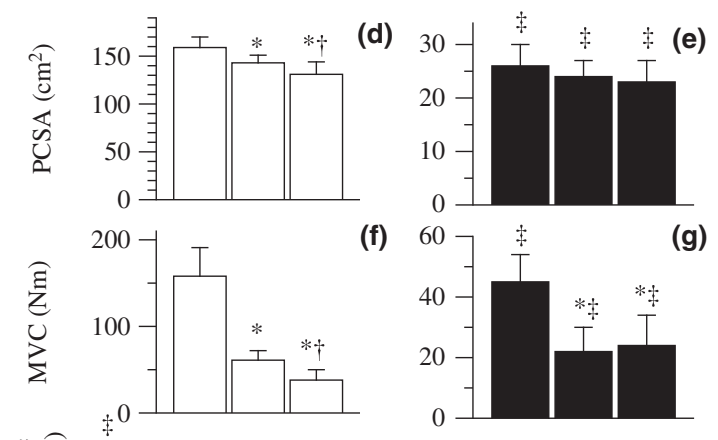

(f)
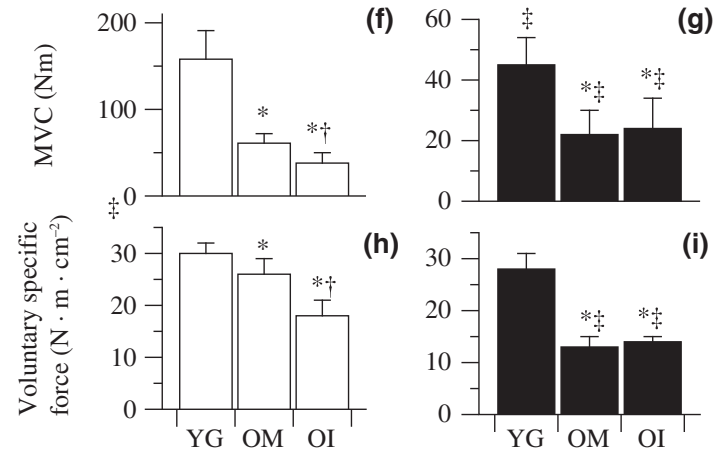

(h)

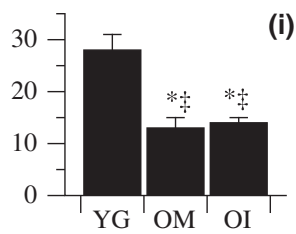

Figure I Muscle mass and maximal voluntary contraction characteristics. Panel (a) 3 mid-thigh and 3 mid-arm magnetic resonance images (MRI) of representative YG, OM and OI subjects. Panels (b-i) document maximal voluntary contraction (MVC), muscle volume of quadriceps (Q) and elbow flexors (EF) calculated from the MRI, physiological cross-sectional areas (PCSA) and maximal voluntary-specific force, respectively, of healthy young (YG), mobile oldest-old (OM) and immobile oldest-old (OI). Data in Panels (b-i) are presented as mean $\pm \mathrm{SE}$; *Significantly different from young subjects; ${ }^{\dagger}$ Significantly different from OM subjects; ${ }^{\star}$ Significant within-group difference between Q and EF.

\section{Muscle mass and maximal voluntary contraction}

As illustrated in the representative T1-weighted images of the upper and lower limbs (Fig. 1, Panel a), there was a marked and progressive thigh muscle atrophy and a greater proportion of fat and connective tissue across the spectrum from $\mathrm{YG}$ to $\mathrm{OM}$ to $\mathrm{OI}$ subjects. This was in stark contrast to the upper arm in which muscle volume clearly remained preserved.
Quantitative analysis supported these visual impressions with a thigh muscle volume of $1844 \pm 230 \mathrm{~cm}^{3}$ in the YG, $1133 \pm 120 \mathrm{~cm}^{3}$ in $\mathrm{OM}$ and $788 \pm 217 \mathrm{~cm}^{3}$ in OI (Fig. 1, Panel b). The upper arm muscle volume was similar between the three groups, $\quad 350 \pm 21 \mathrm{~cm}^{3}, \quad 325 \pm 22 \mathrm{~cm}^{3} \quad$ and $322 \pm 47 \mathrm{~cm}^{3}$ for the YG, OM and OI respectively (Fig. 1, Panel c). Likewise, PCSA of the thigh also fell progressively across the three groups from the $\mathrm{YG}$ $\left(159 \pm 11 \mathrm{~cm}^{2}\right)$ to the OM $\left(143 \pm 8 \mathrm{~cm}^{2}\right)$ to the OI $\left(131 \pm 13 \mathrm{~cm}^{2}\right)$ (Fig. 1, Panel d). While, again, there was no such changes in the PCSA of the upper arm muscle between groups (Fig. 1, Panel e).

Lower-limb MVC was progressively lower than the YG $(158 \pm 33 \mathrm{~N} \mathrm{~m})$ in the $\mathrm{OM}(61 \pm 33 \mathrm{~N} \mathrm{~m})$ and the OI $(38 \pm 12 \mathrm{~N} \mathrm{~m})$ (Fig. 1, Panel f). The MVC of the upper limb was similarly attenuated compared to that of YG $(45 \pm 9 \mathrm{~N} \mathrm{~m})$ in the OM $(22 \pm 8 \mathrm{~N} \mathrm{~m})$ and the OI $(24 \pm 10 \mathrm{~N} \mathrm{~m})$ (Fig. 1, Panel g). Even after the normalization for the PCSA, the maximal force of the quadriceps muscle was progressively diminished across the three groups, with a quadriceps voluntary-specific force of $30 \pm 2 \mathrm{~N} \mathrm{~m} \mathrm{~cm}^{-2}$ in the YG, $26 \pm 3 \mathrm{~N} \mathrm{~m} \mathrm{~cm}^{-2}$ in the $\mathrm{OM}$ and $18 \pm 3 \mathrm{~N} \mathrm{~m} \mathrm{~cm}^{-2}$ in OI (Fig. 1, Panel h). In contrast, in the upper limb, compared to the voluntary-specific force of the $\mathrm{YG}\left(28 \pm 3 \mathrm{~N} \mathrm{~m} \mathrm{~cm}^{-2}\right)$, there was an equal reduction in both the $\mathrm{OM}\left(13 \pm 2 \mathrm{~N} \mathrm{~m} \mathrm{~cm}^{-2}\right)$ and the OI $\left(14 \pm 1 \mathrm{~N} \mathrm{~m} \mathrm{~cm}^{-2}\right)$ (Fig. 1, Panel i). Interestingly, only in the YG was the difference between upper- and lower-limb MVC ablated after the normalization for the PCSA (voluntary-specific force), while both the OM and the OI exhibited an attenuated voluntary-specific force in the upper limb compared to the lower limb (Fig. 1, Panel e).

\section{Neuromuscular activation and RT characteristics}

Representative images of superimposed twitches evoked during the MVCs of the upper and lower limbs are displayed in Figure 2, Panel b. Representative RT tracings in the arm and leg muscle are displayed in Figure 2, Panel c. Voluntary activation of the quadriceps muscle was $94.5 \pm 1.8 \%$ in $\mathrm{YG}$, $85.3 \pm 2.2 \%$ in $\mathrm{OM}$ and $78.2 \pm 3.0 \%$ in OI subjects (Fig. 2, Panel d), whereas voluntary activation of the upper arm muscle was more similar in the YG $(96.2 \pm 1.5 \%), \quad$ OM $\quad(92.3 \pm 2.1 \%) \quad$ and $\mathrm{OI}$ $(91.8 \pm 1.9 \%)$ (Fig. 2, Panel d). The peak quadriceps RT was significantly attenuated compared to the YG $(41.3 \pm 4.2 \mathrm{~N} \mathrm{~m})$ in the $\mathrm{OM}(27.2 \pm 3.1 \mathrm{~N} \mathrm{~m})$ and even more so in the OI $(21.4 \pm 4.4 \mathrm{~N} \mathrm{~m})$ (Fig. 2, Panel $\mathrm{f}$ ). In contrast, peak RT of the upper limbs was not different in the YG, OM and OI $(14.5 \pm 3.6$; $12.2 \pm 4.8 ; \quad 13.6 \pm 3.9 \mathrm{~N} \mathrm{~m}$ respectively) (Fig. 2, 


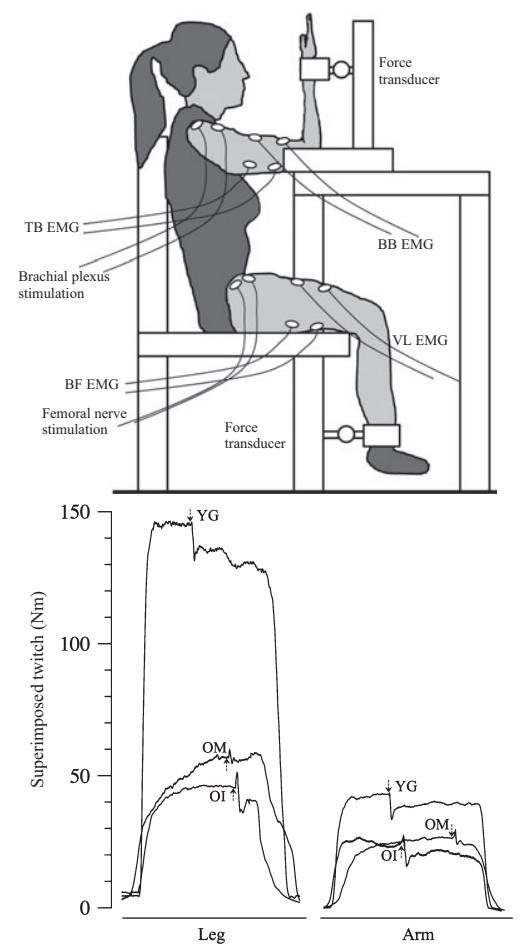

(a)

(b)

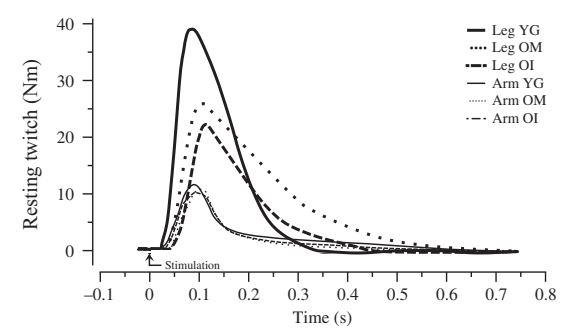

(c)
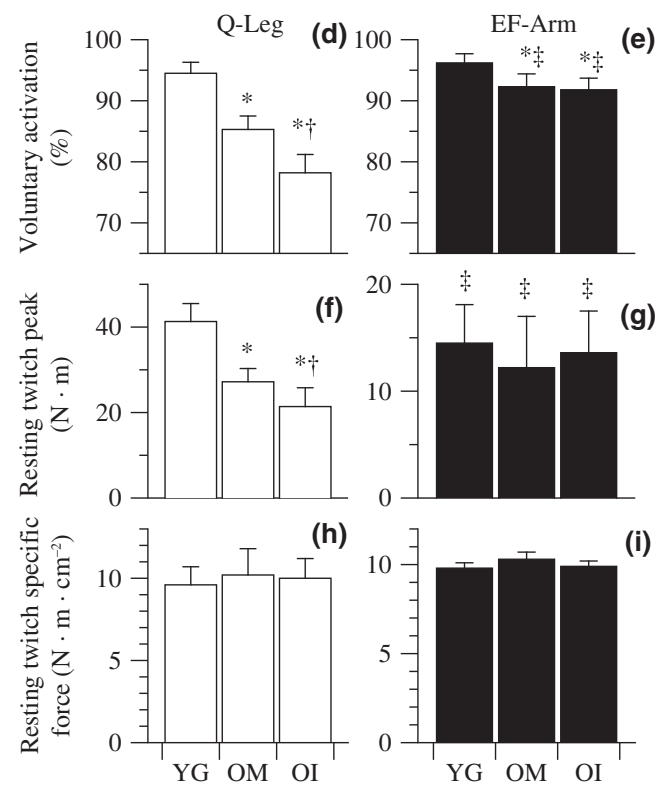

Panel g). Interestingly, by normalizing peak RT for the PCSA, all differences between groups in both upper and lower limbs were ablated (Fig. 2, Panels h,i).
Figure 2 Neuromuscular activation and resting twitch (RT) characteristics. Panel (a) illustrates the in vivo experimental set-up. Panel (b) presents example tracings of the superimposed twitch technique utilized to determine muscle voluntary activation in legs (quadriceps, Q) and arms (elbow flexors, EF). The superimposed twitches (arrows) were imposed at the highest volitional steady-state torque. Representative examples of RT torque-time curves from Q and EF are illustrated in Panel (c). Panels (d-i) document muscle activation, as determined by the superimposed twitch technique, RT peak torque and RT-specific force, respectively, in healthy young (YG), mobile oldest-old (OM) and immobile oldest-old (OI). Data in Panels (d-i) are presented as mean $\pm \mathrm{SE}$; *Significantly different from young subjects; ${ }^{\dagger}$ Significantly different from OM subjects; ${ }^{*}$ Significant withingroup difference between EF and Q.

\section{Fibre type distribution, CSA and single fibre mechanics}

The distribution of the myosin isoforms, taken as molecular markers of fibre type, is illustrated in Figure 3. As documented, the proportion of both MyHC1 and MyHC-2A isoforms were not statistically different in the legs or arms of YG, OM and OI subjects $(P=0.8$; Fig. 3$)$; however, a tendency for a higher proportion of slow-type MyHC-1 was evident in the legs of YG but not in the legs of OM and OI. Conversely, the proportion of MyHC-2X isoform was significantly increased in the upper and lower limbs of both OM (approx. 24\%) and OI (approx. 22\%) in comparison with the YG (approx. 9\%). To ascertain whether the muscle fibre sampled for mechanics were representative of the changes (atrophy) related to disuse, CSA was measured in the fibres belonging to the same sample used for in vitro force measurements, but not mounted on the force analysis system (Fig. 4). Interestingly, in OI lower-limb muscles, a significant population of thin fibres (below $4000 \mu \mathrm{m}^{2}$, approx. 1/ 3 of the total, Fig. 4, Panel a) was detected. A total of 302 single fibres (127 in YG, 91 in OM and 84 in OI) were dissected and characterized for their contractile performance, and the results are reported in Figure 5. The CSA of fibres from the lower limb was similar across the three groups: $4629 \pm 1239 \mu \mathrm{m}^{2}$, $4878 \pm 877 \mu \mathrm{m}^{2}, 4758 \pm 1023 \mu \mathrm{m}^{2}$ in $\mathrm{YG}, \mathrm{OM}$ and OI respectively. Similarly, the CSA of fibres in the upper limb was not different between the YG $\left(3499 \pm 634 \mu \mathrm{m}^{2}\right), \mathrm{OM}\left(3941 \pm 801 \mu \mathrm{m}^{2}\right)$ and $\mathrm{OI}$ $\left(3222 \pm 811 \mu \mathrm{m}^{2}\right)$ (Fig. 5a). However, all the groups exhibited a significantly higher CSA in the fibres of the lower limb compared to the corresponding upper limb. The maximally activated Fo assessed in the fibres dissected from leg muscles was $0.46 \pm 0.09 \mathrm{mN}$ in YG subjects, $0.42 \pm 0.03 \mathrm{mN}$ in $\mathrm{OM}$ and $0.48 \pm 0.03 \mathrm{mN}$ in OI (Fig. 5, Panel b) with no 


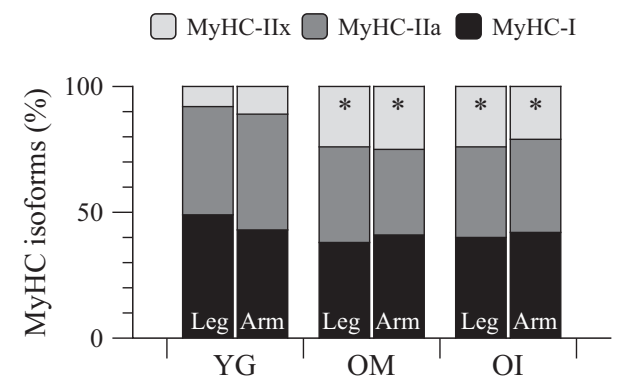

Figure 3 Myosin isoform distribution in leg and arm muscle of healthy young (YG), mobile oldest-old $(\mathrm{OM})$ and immobile oldest-old $(\mathrm{OI})$. *Significantly different from young subjects.

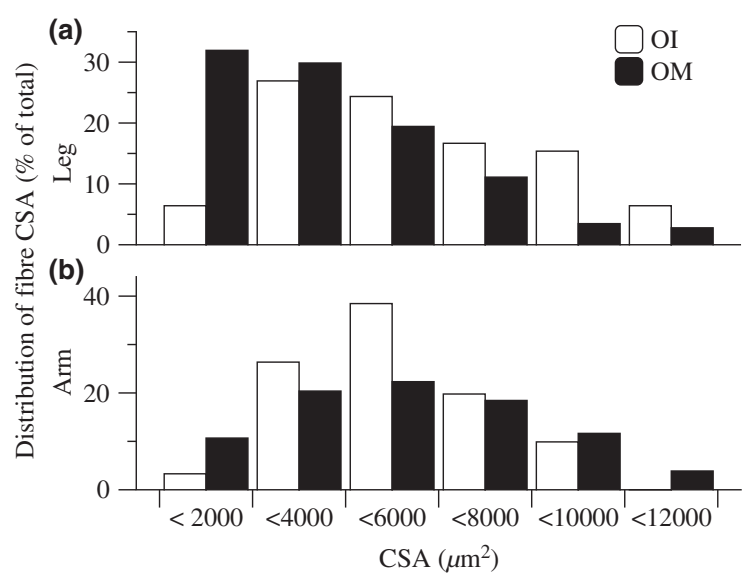

Figure 4 Cross-sectional area (CSA) distribution in fibres from arm and leg muscle of mobile oldest-old (OM) and immobile oldest-old (OI).

difference between groups. In the arms, Fo was $0.41 \pm 0.07 \mathrm{mN}, 0.42 \pm 0.08 \mathrm{mN}$ and $0.38 \pm 0.09$ $\mathrm{mN}$ for YG, OM and OI, respectively, again with no difference between groups (Fig. 5, Panel b). This lack of a difference in single fibre mechanics, this time between YG, OM and OI, as well as between muscle from the upper and lower limbs, also held true when the single fibre data were expressed as Po (Fig. 5, Panel c). Importantly, even when fibres were grouped according to their composition in terms of myosin isoforms, no difference was detectable between YG, OM and OI (Table 2). When fibres were grouped according to their composition in terms of myosin isoforms, very few significant differences were detectable between YG, OM and OI (Table 2). Interestingly, fast $2 \mathrm{~A}$ fibres were thicker and stronger in the biceps of OI.

\section{Discussion}

This study sought to parse out the impact of advanced ageing and disuse on skeletal muscle function. Specifi-
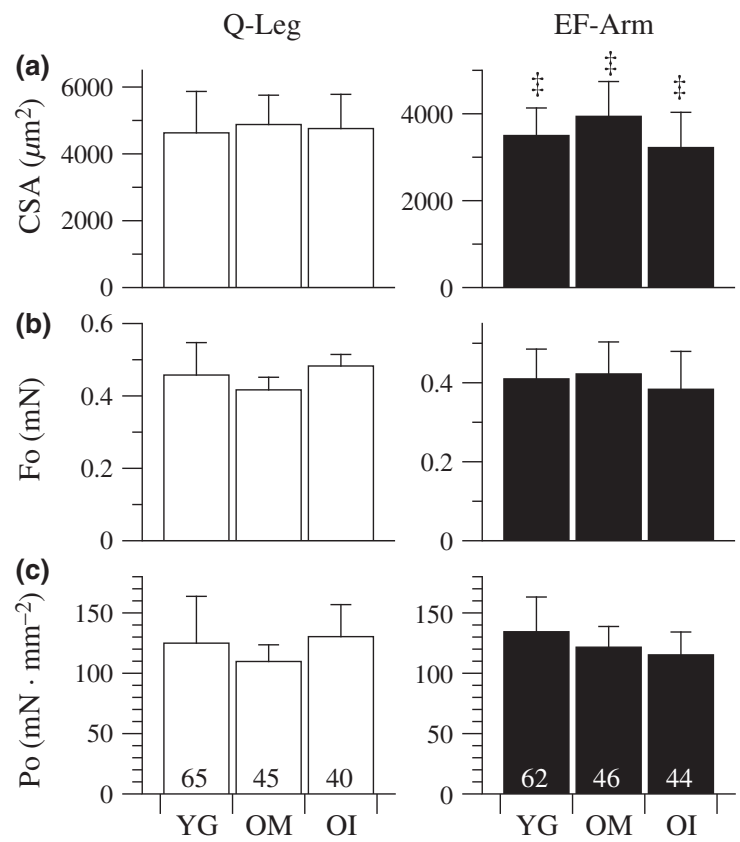

Figure 5 Cross-sectional area (CSA) and single fibre mechanics. Panels $(\mathrm{a}-\mathrm{c})$ illustrate CSA, maximal isometric force $(\mathrm{Fo})$ and specific tension $(\mathrm{Po}=\mathrm{Fo} / \mathrm{CSA})$, respectively, of single fibres from the legs (quadriceps, Q) and arms (elbow flexors, EF) of healthy young (YG), mobile oldest-old (OM) and immobile oldest-old (OI). Data are presented as mean $\pm \mathrm{SE}$; ${ }^{\ddagger}$ Significant within-group difference between EF and $\mathrm{Q}$.

cally, both in vivo and in vitro techniques were utilized to comprehensively assess muscle contractile properties in combination with the innovative approach of assessing both upper- and lower-limb muscle, which experience differing degrees of disuse, in YG, OM and OI subjects. In partial agreement with our first and second hypotheses, the lower-limb muscle of the $\mathrm{OM}$ and $\mathrm{OI}$ subjects, assessed in vivo by volitional muscle contraction, exhibited attenuated muscle function compared to the YG, and this diminished lower-limb function was more pronounced in the OI subjects. Likewise, our third hypothesis, regarding in vivo function in the arms, was also partially correct, revealing an age-related reduction in volitional contraction assessed in vivo. However, in disagreement with all of our hypotheses, the in vitro assessment of YG, OM and OI skinned single skeletal muscle fibres implied preserved intrinsic contractile force in the oldest-old, regardless of age or inactivity. In support of this finding, the muscle twitch parameters, normalized for muscle mass, which reflects in vivo force without the effects of potentially limiting neuromuscular factors, also revealed preserved intrinsic contractile function in all muscles of the oldestold. Moreover, muscle voluntary activation, assessed 
Table 2 In vitro skinned muscle fibre characteristics from the legs (quadriceps, Q) and arms (elbow flexors, EF) of healthy young (YG), mobile oldest-old (OM) and immobile oldest-old (OI). Data relative to the three major fibre types (slow, fast IIA and fast IIA-X) and covering approx. $90 \%$ of the fibre population are shown, whereas the minor groups of mixed I-IIA and pure IIX fibres are omitted

\begin{tabular}{|c|c|c|c|c|c|c|c|}
\hline & \multirow[b]{2}{*}{$\mathrm{MyHC}$} & \multicolumn{3}{|l|}{ Q-Leg } & \multicolumn{3}{|l|}{ EF-Arm } \\
\hline & & I & IIA & IIA-X & I & IIA & IIA-X \\
\hline \multirow[t]{4}{*}{ YG } & $N$ & 27 & 20 & 10 & 20 & 20 & 20 \\
\hline & Fo $(\mathrm{mN})$ & $0.399 \pm 0.044$ & $0.540 \pm 0.055$ & $0.461 \pm 0.024$ & $0.274 \pm 0.031$ & $0.559 \pm 0.080$ & $0.413 \pm 0.020$ \\
\hline & $\operatorname{CSA}\left(\mu \mathrm{m}^{2}\right)$ & $4259 \pm 378$ & $4770 \pm 448$ & $4156 \pm 792$ & $3423 \pm 325$ & $4046 \pm 394$ & $3153 \pm 339$ \\
\hline & Po $\left(\mathrm{mN} \mathrm{mm}^{-2}\right)$ & $105 \pm 12$ & $136 \pm 22$ & $128 \pm 14$ & $88 \pm 11$ & $153 \pm 27$ & $144 \pm 11$ \\
\hline \multirow[t]{4}{*}{$\mathrm{OM}$} & $N$ & 22 & 11 & 10 & 23 & 7 & 10 \\
\hline & Fo $(\mathrm{mN})$ & $0.435 \pm 0.041$ & $0.377 \pm 0.064$ & $0.561 \pm 0.115$ & $0.3756 \pm 0.031$ & $0.411 \pm 0.052$ & $0.535 \pm 0.078$ \\
\hline & $\operatorname{CSA}\left(\mu \mathrm{m}^{2}\right)$ & $5327 \pm 598$ & $3854 \pm 820$ & $4834 \pm 545$ & $4005 \pm 333$ & $3861 \pm 330$ & $3827 \pm 419$ \\
\hline & Po $\left(\mathrm{mN} \mathrm{mm}^{-2}\right)$ & $93 \pm 13$ & $109 \pm 12$ & $112 \pm 14$ & $106 \pm 13$ & $112 \pm 16$ & $146 \pm 23$ \\
\hline \multirow[t]{4}{*}{ OI } & $N$ & 20 & 4 & 10 & 22 & 6 & 10 \\
\hline & Fo $(\mathrm{mN})$ & $0.557 \pm 0.042$ & $0.378 \pm 0.123$ & $0.640 \pm 0.075$ & $0.305 \pm 0.039$ & $0.701 \pm 0.028^{*}$ & $0.431 \pm 0.065$ \\
\hline & $\operatorname{CSA}\left(\mu \mathrm{m}^{2}\right)$ & $5603 \pm 464$ & $2939 \pm 521$ & $3859 \pm 403$ & $3069 \pm 377$ & $6499 \pm 706^{*}$ & $4092 \pm 783$ \\
\hline & Po $\left(\mathrm{mN} \mathrm{mm}^{-2}\right)$ & $111 \pm 12$ & $131 \pm 32$ & $177 \pm 7$ & $108 \pm 8$ & $113 \pm 14$ & $119 \pm 18$ \\
\hline
\end{tabular}

Mean \pm SE. $N$, number of fibres analysed; CSA, cross-sectional area; Fo, maximal isometric force; Po, specific tension; MyHC, myosin heavy chain isoform.

"Significantly different from corresponding values in YG and OM.

with a combination of RT and superimposed twitches, was attenuated with advanced age and more so with disuse. Therefore, it appears that in the oldest-old, neither advanced ageing nor disuse, per se, impacts intrinsic skeletal muscle function, as assessed in vitro and in vivo, but volitional muscle function is attenuated by age and exacerbated by disuse. These findings implicate factors other than skeletal muscle, such as neuromuscular control, in the diminution of skeletal muscle function with advanced ageing and disuse in vivo (Fig. 6).

\section{Differential impact of sarcopenia on the skeletal muscle of the upper and lower limbs}

Despite several investigations emphasizing the greater impact of sarcopenia on lower limbs in comparison with upper limbs, the reason for this difference has not been fully elucidated (Gallagher et al. 1997, Janssen et al. 2000, Narici \& Maffulli 2010). However, it has been speculated that this disparity may be the result of a greater loss of motor units in the legs than in the arms (Galea 1996). Specifically, with advancing age, and especially in the oldest-old, humans are more prone to become less physically active with significant periods of lower-limb disuse (Buford et al. 2012, Pojednic et al. 2012, Dufour et al. 2013), which may accelerate the loss of skeletal muscle mass and subsequently lower-limb force generating capacity (Berg et al. 1997, Venturelli et al. 2012). Conversely, the muscle volume of the upper limbs is less affected by

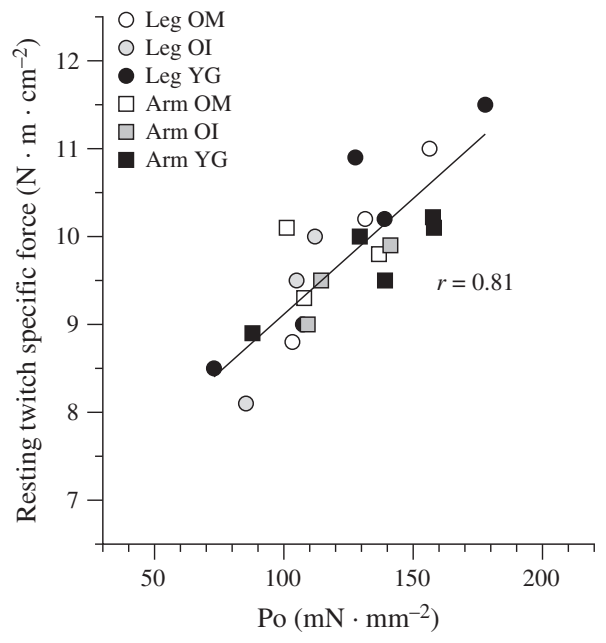

Figure 6 The relationship between intrinsic muscle function measured in vitro, single fibre-specific tension (Po) and in vivo, resting twitch (RT)-specific force. Each point represents the average in vitro and in vivo value obtained from either the leg or arm muscle of a subject ( $n=5$ healthy young (YG), $n=3$ mobile oldest-old (OM) and $n=3$ immobile oldest-old (OI).

the reduction in physical activity across the lifespan (Venturelli et al. 2014), likely because the arms are constantly utilized for the activities of daily living, even in those with mobility limitations (Onder et al. 2005).

Recently, utilizing the same human model of the oldest-old and varying levels of limb disuse, as in the 
current study, our group demonstrated that the progressive fall in skeletal muscle use, as seen in the legs, likely plays a significant role in the exacerbation of cellular ageing and the loss of muscle mass (Venturelli et al. 2014). However, in terms of the impact of sarcopenia, the current findings expand our previous work into the functional consequences of advanced age-related changes in the upper and lower extremities. Specifically, this study reveals that, despite the maintenance of muscle mass in the arms in the oldestold, there was still a significant decrement in voluntary force production in this limb of the OM and OI compared to the YG (Fig. 1, Panel g,i). Although complicated somewhat by clear evidence of sarcopenia in the leg, the equivalent findings of diminished force regardless of muscle mass, achieved by calculating muscle-specific force, are also apparent in the lower limbs, in this case, as a consequence of both advanced age and disuse (Fig. 1, Panel f,h). These first very simplistic observations, supported later by several more complex assessments, imply that the limiting factors for the reduction in force generation capacity with advanced ageing reside outside the contractile machinery of the skeletal muscle cells.

\section{Muscle atrophy and voluntary force production with advanced ageing and disuse}

The results obtained in this study reveal that the loss of muscle mass in the oldest-old was far greater in lower limb than in upper limb where this did not reach statistical significance. The loss of muscle mass is the consequence of a greater loss of muscle fibres, caused by denervation (Doherty et al. 1993), and a reduction in size of the remaining fibres. Interestingly, the assessment of the single fibres utilized for contractile measurements did not reveal this latter effect. This is, however, at least partially, likely due to the involuntary selection of fibres during the manual dissection procedure, which tends to result in the very thin fibres being discarded. Indeed, the assessment of larger muscle tissue samples revealed that in all the oldest-old, but particularly in the OI subjects, a large population of fibres (up to $30 \%$ ) undergo pronounced atrophy.

The relevance of atrophy as explanation for the functional impairment associated with ageing is somewhat controversial. The literature based on cross-sectional studies has indicated that the reduction of in vivo muscle performance with ageing is a direct result of the muscle atrophy (Frontera et al. 1991). However, other longitudinal investigations have suggested a dissociation between the drop of skeletal muscle mass and the consequent decrease in voluntary force among older adults (Goodpaster et al. 2006, Delmonico et al. 2009). For instance, Hughes and co-authors (Hughes et al. 2001) demonstrated that in physically active elderly, morphological variations in the skeletal muscle explained only $5 \%$ of the corresponding decrease in voluntary muscle force. Therefore, this dissociation between atrophy and the more pronounced reduction in skeletal muscle voluntary force with advancing age implies that additional physiological mechanisms are responsible for this phenomenon. Data from the current study are in agreement with these previous findings; in fact, even after the normalization for the PCSA, voluntary-specific force was significantly reduced in both the upper and lower limbs of OM and OI (Fig. 1, Panel e). In this scenario, it has been suggested that age- and disuse-related changes in neural control may play a substantial role in this recognized decline in muscle voluntary force (Delbono 2003, 2011, Payne \& Delbono 2004, Aagaard et al. 2010, Reid et al. 2012).

\section{Single muscle fibre contractile function with advanced ageing and disuse}

Previously, it has been recognized that both ageing and skeletal muscle disuse are related to the progressive impairment in muscle mechanical function assessed in vivo, which may, at least in part, be a consequence of altered single muscle fibre mechanics ( $\mathrm{Yu}$ et al. 2007, Frontera et al. 2008, Aagaard et al. 2010, Canepari et al. 2010a, Callahan et al. 2014a). However, the present study reveals no substantial differences between single fibre size and contractile performance from either the upper or lower limbs of the YG, OM or OI subjects. This unaltered single fibre mechanics (i.e. unchanged tension development) disagrees with some previous findings of an age- and disuse-related decline in single fibre contractile properties (Larsson et al. 1997, Frontera et al. 2000, D'Antona et al. 2003, Ochala et al. 2007, Yu et al. 2007, Callahan et al. 2014b), but is in accordance with other investigations that are more similar to the current work (Raue et al. 2009, Hvid et al. 2010, 2011, Reid et al. 2012). Indeed, the present findings, of maintained single fibre contractile function, in the oldest-old are in best agreement with previous studies that employed a similar in vivo and in vitro approach to compare young and oldest-old subjects (approx. 85 years) (Trappe et al. 2003, Raue et al. 2009). The apparent contrast between the overall decline of muscle mass and performance, assessed in vivo, and the preservation of single fibre function, as determined in vitro, can be viewed as the final result of a progressive selective loss of fibres. Likely in relation to motor neurone death (see below for further discussion), during which many fibres disappear and the surviving fibres undergo compensatory hypertrophy. Another 
factor that may contribute to this phenomena is the age- and inactivity-related changes in skeletal muscle extracellular matrix (Kragstrup et al. 2011). Specifically, in an animal study, it has been demonstrated that exercise training did not prevent the increase of muscle collagen with advancing age (Zimmerman et al. 1993). These findings suggest that the agerelated increase in skeletal muscle extracellular matrix is not just a result of decreasing physical activity with age.

It is well established that ageing and disuse are two stimuli that are critical in determining skeletal muscle phenotype. Specifically, ageing is typically associated with a fast-to-slow fibre type shift, while disuse predominantly results in a slow-to-fast fibre type change (Schiaffino \& Reggiani 2011, Blaauw et al. 2013, Ciciliot et al. 2013). Interestingly, in previous studies, it has been indicated that ageing or disuse can alter the contractile properties of single muscle fibres without evident changes in the fibre type composition. This intriguing observation suggests that single fibre mechanics may change independently from the fibre phenotype (Bottinelli et al. 1999, Canepari et al. 2010a). The current data suggest that the preserved capacity to produce tension of the single skeletal muscle fibres from the OM and $\mathrm{OI}$ is accompanied by significant changes in the distribution of $\mathrm{MyHC}$ isoforms (Figs 3 and 5, Panel c). Indeed, both $\mathrm{OM}$ and $\mathrm{OI}$ showed similar transition towards expression of the fast 2X MyHC isoform (Table 2), implying some degree of limited motor activity, not only in the OI, but also potentially in the OM subjects (Purves-Smith et al. 2014). This is not so surprising given the advanced age of these individuals.

Some important caveat must accompany the discussion of the results obtained on single fibres. In the first place, the number of single fibres analysed represents in all cases a very small fraction of the whole fibre population composing the muscle. This is even more true for this study where a less invasive biopsy technique adopted in this study (14-gauge tru-cut needle) yielded limited, and in some cases insufficient, samples of skeletal muscle tissue for the in vitro measurements. In addition, whenever performing in vitro studies with single skeletal muscle fibres, it is important to take into account a possible unwanted selection of fibres with the thinnest fibres discarded and to underline that the force measurements were performed with maximal calcium activation $(\mathrm{pCa}=4.6)$ and at a temperature lower than the physiological body temperature. Available evidence suggests that such maximal activation is never attained by muscle fibres in vivo, and this may be particularly the case in old subjects. Specifically with regard to ageing, it has been documented that there is a significant age and neural-dependent decrease in dihydropyridine receptor (DHPR) functional expression that is responsible for an uncoupling of the excitation-contraction process that results in an incomplete activation of the myofibrillar machinery (Delbono 2011). Interestingly, exercise and chronic nerve stimulation increase the expression of DHPR (Saborido et al. 1995, Pereon et al. 1997), and this may be one of the mechanisms responsible for the attenuated function in vivo, with both advanced ageing and disuse, which was not evident in vitro.

\section{Neuromuscular factors and voluntary force production with advanced ageing and disuse}

Maximal voluntary force represents the integration of neural, cellular and integrated muscle function (Payne \& Delbono 2004, Aagaard et al. 2010). The current data provide evidence that neuromuscular activation may be a modulator of advanced ageing- and disuserelated decline in muscle voluntary force (Fig. 2, Panels h,i). Specifically, in line with this progressive reduction in voluntary force generation, the lower limbs of the OM and OI exhibited a similar fall in muscle voluntary activation (Fig. 2, Panel d). This reduction in muscle voluntary activation was also apparent in the arms, but likely as there was no evidence of disuse in upper limbs both the OM and OI exhibited the same attenuation (Fig. 2, Panel e). Additional evidence of the potential neuromuscular contribution to the reduction of in vivo force is the RTspecific force. This variable is an indicator of in vivo force without a role for neural drive and PCSA as potentially limiting factors.

With the similar RT-specific force in the arms and legs across the three groups, the reduction in muscle voluntary activation with advanced ageing and disuse, and the good correlation with Po assessed, independently, in vitro $(r=0.81, P \leq 0.05$; Fig. 5$)$, it seems reasonable to assume that a deficit in neural drive plays a significant role in the reduction in voluntary force production with age and disuse. Although this study cannot identify exactly which components of the nervous system are responsible for these age- and disuserelated changes, potential candidates include a reduction in the number of motor neurones, alteration of the motor units and the decrease of neuromuscular activation as a consequence of a decline in maximal motoneurone firing rate (Kamen et al. 1995, Lexell 1997, Aagaard et al. 2010). Moreover, increasing evidence points to a decline in neural influence on skeletal muscle at later ages, and this might also lead to changes in muscle structure which together result in excitation-contraction uncoupling (Delbono 2003). Interestingly, in a recent murine study, it has been revealed that large 
changes in the genes associated with neuromuscular junction denervation, such as Chnrg, Chrnd, Ncam1, Runx1, Gadd45a and Myog, appear to be closely linked to the denervation of ageing myofibres (Barns et al. 2014). Taken together, these studies support the concept that in vivo force characteristics are largely dependent upon neural activity, including a possible involvement of DHPR, and consequently influence excitation-contraction coupling.

\section{Conclusion}

Utilizing a novel human model of advanced age and differential limb disuse, this study has documented that, despite preserved muscle mass in the upper limb, volitional contractile function was attenuated in all limbs of the oldest-old compared to the YG and this difference was exacerbated in the legs by disuse. However, the in vitro assessment of single skeletal muscle fibres implied that neither age nor disuse affected intrinsic skeletal muscle function. This finding was supported by electrically evoked twitches in vivo, which revealed attenuated muscle voluntary activation with advanced age and disuse, but preserved intrinsic contractile function in all muscles of the oldest-old. In combination, these data implicate factors other than skeletal muscle, such a neuromuscular control, in the in vivo attenuation of skeletal muscle function associated with advanced ageing and disuse.

\section{Conflict of interest}

There is no conflict of interest.

We thank doctors Rudi D., Tabarrini N., Vezzani I., and Stefanelli D., for their valuable assistance with the recruitment of the subjects and MRI analyses. This work was supported, in part, by the Programma di Ricerca Scientifica di Rilevante Interesse Nazionale P.R.I.N. 2010KL2Y73_004, the Mons. Arrigo Mazzali Foundation, National Heart, Lung, and Blood Institute (HL 09183); and the Veterans Administration (Merit Grant E6910R).

\section{References}

Aagaard, P., Suetta, C., Caserotti, P., Magnusson, S.P. \& Kjaer, M. 2010. Role of the nervous system in sarcopenia and muscle atrophy with aging: strength training as a countermeasure. Scand J Med Sci Sports 20, 49-64.

Barns, M., Gondro, C., Tellam, R.L., Radley-Crabb, H.G., Grounds, M.D. \& Shavlakadze, T. 2014. Molecular analyses provide insight into mechanisms underlying sarcopenia and myofibre denervation in old skeletal muscles of mice. Int J Biochem Cell Biol 53, 174-185.

Berg, H.E., Larsson, L. \& Tesch, P.A. 1997. Lower limb skeletal muscle function after $6 \mathrm{wk}$ of bed rest. J Appl Physiol 82, 182-188.
Blaauw, B., Schiaffino, S. \& Reggiani, C. 2013. Mechanisms modulating skeletal muscle phenotype. Compr Physiol 3, 1645-1687.

Bottinelli, R., Pellegrino, M.A., Canepari, M., Rossi, R. \& Reggiani, C. 1999. Specific contributions of various muscle fibre types to human muscle performance: an in vitro study. J Electromyogr Kinesiol 9, 87-95.

Buford, T.W., Lott, D.J., Marzetti, E., Wohlgemuth, S.E., Vandenborne, K., Pahor, M., Leeuwenburgh, C. \& Manini, T.M. 2012. Age-related differences in lower extremity tissue compartments and associations with physical function in older adults. Exp Gerontol 47, 38-44.

Callahan, D.M., Bedrin, N.G., Subramanian, M., Berking, J., Ades, P.A., Toth, M.J. \& Miller, M.S. 2014a. Age-related structural alterations in human skeletal muscle fibers and mitochondria are sex specific: relationship to single-fiber function. J Appl Physiol (1985), 116, 1582-1592.

Callahan, D.M., Miller, M.S., Sweeny, A.P., Tourville, T.W., Slauterbeck, J.R., Savage, P.D., Maugan, D.W., Ades, P.A., Beynnon, B.D. \& Toth, M.J. 2014b. Muscle disuse alters skeletal muscle contractile function at the molecular and cellular levels in older adult humans in a sex-specific manner. J Physiol 592, 4555-4573.

Campbell, E.L., Seynnes, O.R., Bottinelli, R., McPhee, J.S., Atherton, P.J., Jones, D.A., Butler-Browne, G. \& Narici, M.V. 2013. Skeletal muscle adaptations to physical inactivity and subsequent retraining in young men. Biogerontology 14, 247-259.

Canepari, M., Pellegrino, M.A., D’Antona, G. \& Bottinelli, R. 2010a. Single muscle fiber properties in aging and disuse. Scand J Med Sci Sports 20, 10-19.

Canepari, M., Pellegrino, M.A., D’Antona, G. \& Bottinelli, R. 2010b. Skeletal muscle fibre diversity and the underlying mechanisms. Acta Physiol (Oxf) 199, 465-476.

Ciciliot, S., Rossi, A.C., Dyar, K.A., Blaauw, B. \& Schiaffino, S. 2013. Muscle type and fiber type specificity in muscle wasting. Int J Biochem Cell Biol 45, 2191-2199.

D’Antona, G., Pellegrino, M.A., Adami, R., Rossi, R., Carlizzi, C.N., Canepari, M., Saltin, B. \& Bottinelli, R. 2003. The effect of ageing and immobilization on structure and function of human skeletal muscle fibres. J Physiol 552, 499-511.

Delbono, O. 2003. Neural control of aging skeletal muscle. Aging Cell 2, 21-29.

Delbono, O. 2011. Expression and regulation of excitationcontraction coupling proteins in aging skeletal muscle. Curr Aging Sci 4, 248-259.

Delmonico, M.J., Harris, T.B., Visser, M., Park, S.W., Conroy, M.B., Velasquez-Mieyer, P., Boudreau, R., Manini, T.M., Nevitt, M., Newman, A.B., Goodpaster, B.H., for the Health, Aging, and Body Composition Study. 2009. Longitudinal study of muscle strength, quality, and adipose tissue infiltration. Am J Clin Nutr, 90, 1579-1585.

Deschenes, M.R., Britt, A.A. \& Chandler, W.C. 2001. A comparison of the effects of unloading in young adult and aged skeletal muscle. Med Sci Sports Exerc 33, 14771483.

Doherty, T.J. 2003. Invited review: aging and sarcopenia. J Appl Physiol 95, 1717-1727. 
Doherty, T.J., Vandervoort, A.A., Taylor, A.W. \& Brown, W.F. 1993. Effects of motor unit losses on strength in older men and women. J Appl Physiol (1985), 74, 868874.

Doria, C., Toniolo, L., Verratti, V., Cancellara, P., Pietrangelo, T., Marconi, V., Paoli, A., Pogliaghi, S., Fano, G., Reggiani, C. \& Capelli, C. 2011. Improved VO2 uptake kinetics and shift in muscle fiber type in high-altitude trekkers. J Appl Physiol (1985), 111, 1597-1605.

Dufour, A.B., Hannan, M.T., Murabito, J.M., Kiel, D.P. \& McLean, R.R. 2013. Sarcopenia definitions considering body size and fat mass are associated with mobility limitations: the Framingham Study. J Gerontol A Biol Sci Med Sci 68, 168-174.

Erskine, R.M., Jones, D.A., Maganaris, C.N. \& Degens, H. 2009. In vivo specific tension of the human quadriceps femoris muscle. Eur J Appl Physiol 106, 827-838.

Fielding, R.A., Vellas, B., Evans, W.J., Bhasin, S., Morley, J.E., Newman, A.B., Abellan van Kan, G., Andrieu, S., Bauer, J., Breuille, D. et al. 2011. Sarcopenia: an undiagnosed condition in older adults. Current consensus definition: prevalence, etiology, and consequences. International working group on sarcopenia. J Am Med Dir Assoc 12, 249-256.

Frontera, W.R., Hughes, V.A., Lutz, K.J. \& Evans, W.J. 1991. A cross-sectional study of muscle strength and mass in 45- to 78-yr-old men and women. J Appl Physiol (1985), 71, 644-650.

Frontera, W.R., Suh, D., Krivickas, L.S., Hughes, V.A., Goldstein, R. \& Roubenoff, R. 2000. Skeletal muscle fiber quality in older men and women. Am J Physiol Cell Physiol 279, C611-C618.

Frontera, W.R., Reid, K.F., Phillips, E.M., Krivickas, L.S., Hughes, V.A., Roubenoff, R. \& Fielding, R.A. 2008. Muscle fiber size and function in elderly humans: a longitudinal study. J Appl Physiol (1985), 105, 637-642.

Galea, V. 1996. Changes in motor unit estimates with aging. J Clin Neurophysiol 13, 253-260.

Gallagher, D., Visser, M., De Meersman, R.E., Sepulveda, D., Baumgartner, R.N., Pierson, R.N., Harris, T. \& Heymsfield, S.B. 1997. Appendicular skeletal muscle mass: effects of age, gender, and ethnicity. J Appl Physiol (1985), 83, 229-239.

Goodpaster, B.H., Park, S.W., Harris, T.B., Kritchevsky, S.B., Nevitt, M., Schwartz, A.V., Simonsick, E.M., Tylavsky, F.A., Visser, M. \& Newman, A.B. 2006. The loss of skeletal muscle strength, mass, and quality in older adults: the health, aging and body composition study. J Gerontol A Biol Sci Med Sci 61, 1059-1064.

Hakkinen, K., Kallinen, M., Izquierdo, M., Jokelainen, K., Lassila, H., Malkia, E., Kraemer, W.J., Newton, R.U. \& Alen, M. 1998. Changes in agonist-antagonist EMG, muscle CSA, and force during strength training in middle-aged and older people. J Appl Physiol (1985), 84, 1341-1349.

Hughes, V.A., Frontera, W.R., Wood, M., Evans, W.J., Dallal, G.E., Roubenoff, R. \& Fiatarone Singh, M.A. 2001. Longitudinal muscle strength changes in older adults: influence of muscle mass, physical activity, and health. J Gerontol A Biol Sci Med Sci 56, B209-B217.
Hvid, L., Aagaard, P., Justesen, L., Bayer, M.L., Andersen, J.L., Ortenblad, N., Kjaer, M. \& Suetta, C. 2010. Effects of aging on muscle mechanical function and muscle fiber morphology during short-term immobilization and subsequent retraining. J Appl Physiol (1985), 109, 1628-1634.

Hvid, L.G., Ortenblad, N., Aagaard, P., Kjaer, M. \& Suetta, C. 2011. Effects of ageing on single muscle fibre contractile function following short-term immobilisation. J Physiol 589, 4745-4757.

Izquierdo, M., Aguado, X., Gonzalez, R., Lopez, J.L. \& Hakkinen, K. 1999. Maximal and explosive force production capacity and balance performance in men of different ages. Eur J Appl Physiol Occup Physiol 79, 260-267.

Janssen, I., Heymsfield, S.B., Wang, Z.M. \& Ross, R. 2000. Skeletal muscle mass and distribution in 468 men and women aged 18-88 yr. J Appl Physiol (1985), 89, 81-88.

Janssen, I., Heymsfield, S.B. \& Ross, R. 2002. Low relative skeletal muscle mass (sarcopenia) in older persons is associated with functional impairment and physical disability. $J$ Am Geriatr Soc 50, 889-896.

Kamen, G., Sison, S.V., Du, C.C. \& Patten, C. 1995. Motor unit discharge behavior in older adults during maximaleffort contractions. J Appl Physiol (1985), 79, 1908-1913.

Kragstrup, T.W., Kjaer, M. \& Mackey, A.L. 2011. Structural, biochemical, cellular, and functional changes in skeletal muscle extracellular matrix with aging. Scand J Med Sci Sports 21, 749-757.

Larsson, L., Li, X. \& Frontera, W.R. 1997. Effects of aging on shortening velocity and myosin isoform composition in single human skeletal muscle cells. Am J Physiol 272, C638-C649.

Lexell, J. 1997. Evidence for nervous system degeneration with advancing age. J Nutr 127, 1011S-1013S.

Maganaris, C.N., Baltzopoulos, V., Ball, D. \& Sargeant, A.J. 2001. In vivo specific tension of human skeletal muscle. $J$ Appl Physiol (1985), 90, 865-872.

Merton, P.A. 1954. Voluntary strength and fatigue. J Physiol, 123, 553-564.

Metter, E.J., Talbot, L.A., Schrager, M. \& Conwit, R. 2002. Skeletal muscle strength as a predictor of all-cause mortality in healthy men. J Gerontol A Biol Sci Med Sci 57, B359-B365.

Murray, W.M., Buchanan, T.S. \& Delp, S.L. 2000. The isometric functional capacity of muscles that cross the elbow. J Biomech 33, 943-952.

Narici, M.V. \& Maffulli, N. 2010. Sarcopenia: characteristics, mechanisms and functional significance. $\mathrm{Br}$ Med Bull 95, 139-159.

Ochala, J., Frontera, W.R., Dorer, D.J., Van Hoecke, J. \& Krivickas, L.S. 2007. Single skeletal muscle fiber elastic and contractile characteristics in young and older men. $J$ Gerontol A Biol Sci Med Sci 62, 375-381.

Onder, G., Penninx, B.W., Ferrucci, L., Fried, L.P., Guralnik, J.M. \& Pahor, M. 2005. Measures of physical performance and risk for progressive and catastrophic disability: results from the Women's Health and Aging Study. J Gerontol A Biol Sci Med Sci 60, 74-79.

Paoli, A., Pacelli, Q.F., Toniolo, L., Miotti, D. \& Reggiani, C. 2010. Latissimus dorsi fine needle muscle biopsy: a 
novel and efficient approach to study proximal muscles of upper limbs. J Surg Res 164, e257-e263.

Payne, A.M. \& Delbono, O. 2004. Neurogenesis of excitation-contraction uncoupling in aging skeletal muscle. Exerc Sport Sci Rev 32, 36-40.

Pereon, Y., Navarro, J., Hamilton, M., Booth, F.W. \& Palade, P. 1997. Chronic stimulation differentially modulates expression of mRNA for dihydropyridine receptor isoforms in rat fast twitch skeletal muscle. Biochem Biophys Res Commun 235, 217-222.

Petrella, J.K., Kim, J.S., Mayhew, D.L., Cross, J.M. \& Bamman, M.M. 2008. Potent myofiber hypertrophy during resistance training in humans is associated with satellite cell-mediated myonuclear addition: a cluster analysis. $J$ Appl Physiol (1985), 104, 1736-1742.

Pojednic, R.M., Clark, D.J., Patten, C., Reid, K., Phillips, E.M. \& Fielding, R.A. 2012. The specific contributions of force and velocity to muscle power in older adults. Exp Gerontol 47, 608-613.

Powell, P.L., Roy, R.R., Kanim, P., Bello, M.A. \& Edgerton, V.R. 1984. Predictability of skeletal muscle tension from architectural determinations in guinea pig hindlimbs. J Appl Physiol Respir Environ Exerc Physiol 57, 1715-1721.

Purves-Smith, F.M., Sgarioto, N. \& Hepple, R.T. 2014. Fiber typing in aging muscle. Exerc Sport Sci Rev 42, 45-52.

Raue, U., Slivka, D., Minchev, K. \& Trappe, S. 2009. Improvements in whole muscle and myocellular function are limited with high-intensity resistance training in octogenarian women. J Appl Physiol (1985), 106, 1611-1617.

Reid, K.F., Doros, G., Clark, D.J., Patten, C., Carabello, R.J., Cloutier, G.J., Phillips, E.M., Krivickas, L.S., Frontera, W.R. \& Fielding, R.A. 2012. Muscle power failure in mobility-limited older adults: preserved single fiber function despite lower whole muscle size, quality and rate of neuromuscular activation. Eur J Appl Physiol 112, 2289-2301.

Saborido, A., Molano, F., Moro, G. \& Megias, A. 1995. Regulation of dihydropyridine receptor levels in skeletal and cardiac muscle by exercise training. Pflugers Arch 429 , 364-369.

Sandiford, S.D., Green, H.J., Duhamel, T.A., Schertzer, J.D., Perco, J.D. \& Ouyang, J. 2005. Muscle Na-K-pump and fatigue responses to progressive exercise in normoxia and hypoxia. Am J Physiol Regul Integr Comp Physiol 289, R441-R449.

Sayer, A.A., Robinson, S.M., Patel, H.P., Shavlakadze, T., Cooper, C. \& Grounds, M.D. 2013. New horizons in the pathogenesis, diagnosis and management of sarcopenia. Age Ageing 42, 145-150.

Schiaffino, S. \& Reggiani, C. 2011. Fiber types in mammalian skeletal muscles. Physiol Rev 91, 1447-1531.

Suetta, C. \& Kjaer, M. 2010. What are the mechanisms behind disuse and age-related skeletal muscle atrophy? Scand J Med Sci Sports 20, 167-168.
Suetta, C., Aagaard, P., Rosted, A., Jakobsen, A.K., Duus, B., Kjaer, M. \& Magnusson, S.P. 2004. Training-induced changes in muscle CSA, muscle strength, EMG, and rate of force development in elderly subjects after long-term unilateral disuse. J Appl Physiol (1985), 97, 1954-1961.

Suetta, C., Aagaard, P., Magnusson, S.P., Andersen, L.L., Sipila, S., Rosted, A., Jakobsen, A.K., Duus, B. \& Kjaer, M. 2007. Muscle size, neuromuscular activation, and rapid force characteristics in elderly men and women: effects of unilateral long-term disuse due to hip-osteoarthritis. J Appl Physiol (1985), 102, 942-948.

Suetta, C., Hvid, L.G., Justesen, L., Christensen, U., Neergaard, K., Simonsen, L., Ortenblad, N., Magnusson, S.P., Kjaer, M. \& Aagaard, P. 2009. Effects of aging on human skeletal muscle after immobilization and retraining. J Appl Physiol (1985), 107, 1172-1180.

Talmadge, R.J. \& Roy, R.R. 1993. Electrophoretic separation of rat skeletal muscle myosin heavy-chain isoforms. $J$ Appl Physiol (1985), 75, 2337-2340.

Tinetti, M.E. 1986. Performance-oriented assessment of mobility problems in elderly patients. J Am Geriatr Soc 34, 119-126.

Toniolo, L., Maccatrozzo, L., Patruno, M., Pavan, E., Caliaro, F., Rossi, R., Rinaldi, C., Canepari, M., Reggiani, C. \& Mascarello, F. 2007. Fiber types in canine muscles: myosin isoform expression and functional characterization. Am J Physiol Cell Physiol 292, C1915-C1926.

Trappe, S., Gallagher, P., Harber, M., Carrithers, J., Fluckey, J. \& Trappe, T. 2003. Single muscle fibre contractile properties in young and old men and women. J Physiol 552, 47-58.

Vandervoort, A.A. 2002. Aging of the human neuromuscular system. Muscle Nerve 25, 17-25.

Venturelli, M., Schena, F. \& Richardson, R.S. 2012. The role of exercise capacity in the health and longevity of centenarians. Maturitas 73, 115-120.

Venturelli, M., Morgan, G.R., Donato, A.J., Reese, V., Bottura, R., Tarperi, C., Milanese, C., Schena, F., Reggiani, C., Naro, F., Cawthon, R.M. \& Richardson, R.S. 2014. Cellular aging of skeletal muscle: telomeric and free radical evidence that physical inactivity is responsible and not age. Clin Sci (Lond) 127, 5.

Yozbatiran, N., Der-Yeghiaian, L. \& Cramer, S.C. 2008. A standardized approach to performing the action research arm test. Neurorehabil Neural Repair 22, 78-90.

Yu, F., Hedstrom, M., Cristea, A., Dalen, N. \& Larsson, L. 2007. Effects of ageing and gender on contractile properties in human skeletal muscle and single fibres. Acta Physiol (Oxf) 190, 229-241.

Zimmerman, S.D., McCormick, R.J., Vadlamudi, R.K. \& Thomas, D.P. 1993. Age and training alter collagen characteristics in fast- and slow-twitch rat limb muscle. J Appl Physiol (1985), 75, 1670-1674. 